\title{
FREQUENCY OF HYPONATREMIA IN COMMUNITY ACQUIRED PNEUMONIA.
}

1. MBBS, FCPS

Senior Registrar Pediatrics Services Hospital, Lahore.

2. MBBS, FCPS (Paeds)

Assistant Professor

Services Hospital, Lahore.

3. MBBS, FCPS (Pediatrics) Assistant Professor Services Hospital, Lahore.

4. MBBS, FCPS

PGR Pediatric Medicine

The Children's Hospital and

The Institute of Child Health, Multan.

5. MBBS, FCPS (Peads)

Assistant Professor

Services Hospital, Lahore.

6. MBBS, FPCS

Assistant Professor Pediatrics

Services Hospital, Lahore.

\section{Correspondence Address:}

Dr. Zeeshan Mehmood

Senior registrar of Pediatrics

Services hospital Lahore.

mehmoodzeeshan245@gmail.com

Article received on:

24/04/2019

Accepted for publication:

25/10/2019

\section{INTRODUCTION}

Community-acquired pneumonia (CAP) is common among children all over the world, but its incidence and mortality rates are significantly higher in developing countries. ${ }^{1,2}$ The estimated incidence of childhood hospitalization due to CAP is $8.7 \%$ of all cases of CAP in developing countries in comparison to $0.3 \%$ in the developed world. ${ }^{2}$ Each year, approximately 1.6 million children die from pneumonia. $^{3}$ Viruses cause a significant percentage of CAP infections, especially in children younger than two years. ${ }^{4}$

Most of the respiratory diseases are thought to be viral infections. Respiratory syncytial virus, influenza $A$, and parainfluenza types 1 through 3 are the most common viral agents. Other viral pathogens include adenovirus, rhinovirus, influenza B, and enteroviruses. Human metapneumovirus has been identified as a common cause of CAP in cases previously classified as virus-negative. The spectrum of illness caused by metapneumovirus is similar to that of respiratory syncytial virus. Mixed viral and bacterial infection accounts for nearly half of all CAP infections in children. ${ }^{5}$

CAP may result in a number of different renal and electrolyte complications. The measurement of serum electrolytes may be helpful in assessing the degree of dehydration in children with limited fluid intake and whether hyponatremia is present (as pneumonia may be complicated by syndrome of inappropriate antidiuretic hormone secretion $(\mathrm{SIADH}){ }^{6}$

Regarding the frequency of hypnatremia in children with CAP, variable results are found in different studies. ${ }^{7}$ Another study recorded these findings (i.e. hyponatremia) in $27.9 \%$ of the cases 
with CAP. $^{8}$ Similarly another study recorded hyponatremia to be present in $45.4 \%$ of children with $\mathrm{CAP}^{9}$

The rationale of the study was that no local literature is available to address this issue while international studies are showing a significant difference which needs to be verified in our local population so that the actual frequency of the hyponatremia in CAP may be determined which will be helpful for the pediatricians for timely prevention of complications of hyponatremia e.g. increased hospitalization stay, cerebral edema, seizures, coma and death in CAP.

\section{MATERIAL \& METHODS}

This cross sectional study was conducted at the Department of Pediatrics, Services Hospital, Lahore, from July 2018 to January 2019

Approval from institutional ethical and research committee was acquired for this study.

A total of 100 diagnosed cases of CAP during the last 72 hours, were enrolled. All cases were up to 2 years of age. All cases who were already diagnosed of hyponatremia and/or having any previous history of hyponatremia were excluded from the study. Verbal consent was taken from parents or guardians of all the study cases.

CAP was labeled as tachypnea (respiratory rate $>50$ breaths per minute in $<1$ year of age case, and respiratory rate $>40$ breaths per minute in $>$ 1 year of age), fever (temperatre $>37^{\circ} \mathrm{C}$ ), chest in-drawing (assessed clinically) and inability to feed orally. Hyponatremia was considered if serum sodium concentration was recorded as less than $136 \mathrm{mg} / \mathrm{dl}$ at the time of admission of children with CAP. It was assessed through $5 \mathrm{cc}$ venous blood sent to the hospital laboratory with the help of paramedical staff.

Demographic profile, age and gender were recorded for all the study participants. The data was analyzed through SPSS version 16. Mean and sd was calculated for age, duration of hospitalization. Frequency and percentage was calculated for categorical variable i.e. gender and presence/absence of hyponatremia.

\section{RESULTS}

Out of 100 cases, there were 57 (57.0\%) male and 43 (43.0\%) female. There were 45 (45.0\%) cases who were less than 1 year of age while 55 (55.0\%) were between 1-2 years of age. Mean age amongst cases was noted as 1.55 years with standard deviation of 0.52 years. There were $63(63.0 \%)$ cases who belonged to rural area of residence while 37 (37.0\%) belonged to urban area of residence. Mean duration of hospitalization was recorded as 4.57 days with a standard deviation of 1.48 days.

Frequency of hyponatremia in children with CAP was recorded in 24 (24.0\%) whereas 76 (76.0\%) had no findings of hyponatremia.

\begin{tabular}{|l|l|c|}
\hline \multicolumn{2}{|c|}{ Characteristics } & Number (\%) \\
\hline \multirow{2}{*}{ Gender } & Male & $57(57.0 \%)$ \\
\cline { 2 - 3 } & Female & $43(43.0 \%)$ \\
\hline \multirow{2}{*}{ Age } & $<1$ year & $45(45.0 \%)$ \\
\hline \multirow{2}{*}{ Area of Residence } & 1 to 2 years & $55(55.0 \%)$ \\
\hline \multirow{2}{*}{$\begin{array}{l}\text { Duration of } \\
\text { Hospital stay }\end{array}$} & Rural & $63(63.0 \%)$ \\
\hline
\end{tabular}

Table-I. Characteristics of study cases $(n=100)$

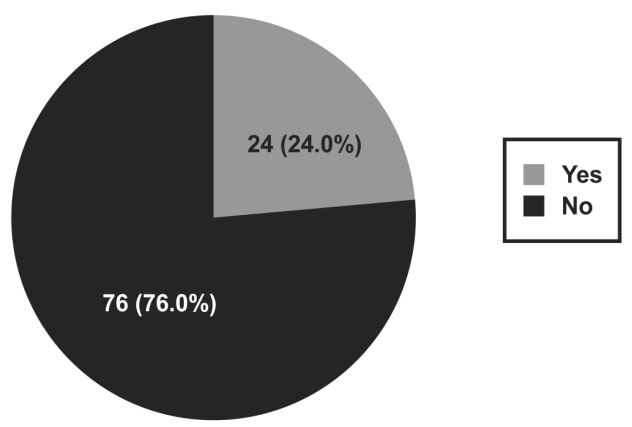

Figure-1. Frequency of hyponatremia in children with CAP $(n=100)$

\section{DISCUSSION}

The current study was planned with the view that no local literature is available to address this issue while international studies are showing a significant difference which needs another study to be conducted in our local population 
so that the actual frequency of the morbidity may be determined which may be helpful for the pediatricians for timely prevention of complications of hyponatremia e.g. increased hospitalization stay, cerebral edema, seizures, coma and death in community acquired penumonia.

We compared our results with the previous study done by Wrotek $A$ and others evaluated the relation between hyponatremia and community-acquired pneumonia (CAP) in children and recorded in $33.3 \%$ of the cases. ${ }^{10}$ Another study recorded these findings (i.e. hyponatremia) in $27.9 \%$ of the cases (with CAP). ${ }^{8}$ The findings of our study are in agreement with the above studies, while another study recorded it in $45.4 \%$ of children with community acquired pneumonia. ${ }^{11}$ These findings are higher than our results.

In children with CAP, Don $\mathrm{M}$, et $\mathrm{al}^{9}$ was of the view that mild hyponatremia is more commonly seen. Raised levels of atrial natriuretic peptide (ANP) have been documented to contribute as ANP adjusts various physiological parameters including diuresis and natriuresis. Raised levels of ANP have been associated with hypoxia that may go on to contribute to pulmonary vasoconstriction as well as right-heart overload. ${ }^{12,13}$

Severe hyponatremia is not common in children having CAP, but being the limitation of this study, we did not analyzed severity of hyponatremia. Gerigk $\mathrm{M}$ and coworkers ${ }^{14}$ found that antidiuretic hormone $(A D H)$ may originate hyponatremia which in turn could cause a non osmotic, cardiovascular mechanism in cases affected by CAP.

Hyponatremia is known to be the commonest electrolyte derangement found in children who are hospitalized. Hyponatremia has also been associated with poor outcomes in pediatric population affected with pneumonia. $^{15} \mathrm{~A}$ combination of hyponatremia and CAP has been noted to contribute to prolonged duration of hospital admissions as well having poor prognosis. ${ }^{7}$ Frequency of hyponatremia was found to be $28 \%$ in children with CAP at the time of admission in a study conducted by
Zilberberg MD and colleagues. ${ }^{15}$ However, we aimed only to record the current frequency of Hyponatremia in our setting, which may be helpful for the pediatricians for timely prevention of complications of hyponatremia e.g. increased hospitalization stay, cerebral edema, seizures, coma and death in CAP. Further studies involving bigger sample size and multiple centers will further verify the findings of this and previously conducted studies.

\section{CONCLUSION}

Frequency of hyponatremia was high (24.0\%) among children with CAP. Every patient who present with CAP should be evaluated for hyponatremia. However, it is also required that every setup should have their surveillance in order to know the frequency of the problem.

Copyright@ 25 Oct, 2019.

\section{REFERENCES}

1. World health organization pneumonia fact sheet updated September 2016.

2. Principi N, Esposito S. Management of severe community-acquired pneumonia of children in developing and developed countries. Thorax 2011; 66:815-22.

3. Gilani Z, Kwong YD, Levine OS, Deloria-Knoll M, Scott JAG. A literature review and survey of childhood pneumonia etiology studies: 2000-2010. Clin Infect Dis 2012; 54 (suppl 2): S102-8.

4. Black RE, Cousens S, Johnson HL. Global, regional, and national causes of child mortality in 2008: A systematic analysis. Lancet. 2012; 375(9730):196919.

5. Rodrigues CM, Groves H. Community-acquired pneumonia in children: The challenges of microbiological diagnosis. J Clin Microbiol. 2018; 56(3): e01318-17.

6. Barson WJ. Community-acquired pneumonia in children: Clinical features and diagnosis. Uptodate 2015; available at: http://www.uptodate.com/ contents/ community-acquired-pneumonia-in-children-clinicalfeatures-and-diagnosis.

7. Mandal PP, Grag M, Choudhary IP. To study the association and significance of hyponatremia in pneumonia in paediatric patients treated in hospital setting. IJCMR 2018; 5(1):11-4. 
8. Nair V, Niederman MS, Masani N, Fishbane S. Hyponatremia in community acquired pneumonia. Am J Nephrol. 2007; 27(2):184-90.

9. Don M, Valerio G, Korppi M, Canciani M. Hyponatremia in pediatric community-acquired pneumonia. Pediatr Nephrol. 2008 Dec; 23(12):2247-53.

10. Wrotek A, Jackowska T. Hyponatremia in children hospitalized due to pneumonia. Adv Exp Med Biol. 2013; 788:103-8.

11. Haviv M, Haver E, Lichtstein D, Hurvitz H, Klar A. Atrial natriuretic peptide in children with pneumonia. Pediatr Pulmonol. 2005; 40:306-9.
12. Yap LB, Mukerjee D, Timms PM, Ashrafian H, Coghlan JG. Natriuretic peptides, respiratory disease, and the right heart. Chest. 2004; 126:1330-6.

13. Wilkins MR, Redondo J, Brown LA. The natriureticpeptide family. Lancet. 1997; 349:1307-10.

14. Gerigk M, Gnehm HE, Rascher W. Arginine vasopressin and renin in acutely ill children: implication for fluid therapy. Acta Paediatr. 1996; 85:550-3.

15. Zilberberg MD, Exuzides A, Spalding J. Epidemiology, clinical and economic outcomes of admission hyponatremia among hospitalized patients. Curr Med Res Opin. 2008; 24:1601-8.

\begin{tabular}{|c|c|c|c|}
\hline \multicolumn{4}{|c|}{ AUTHORSHIP AND CONTRIBUTION DECLARATION } \\
\hline Sr. \# & Author(s) Full Name & Contribution to the paper & Author(s) Signature \\
\hline 1 & Zeeshan Mehmood & $\begin{array}{l}\text { Methodology, Data collection, } \\
\text { Review of Literature review. }\end{array}$ & \\
\hline 2 & Farrukh Saeed & $\begin{array}{l}\text { Supervision, Methodology, } \\
\text { Discussion. }\end{array}$ & \\
\hline 3 & M. Asif Siddiqui & Methodology, Discussion. & Apsffe \\
\hline 4 & Fazal Ur Rehman & Data analysis, Drafting. & 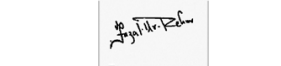 \\
\hline 5 & Farhan Zahoor & Study design, Discussion & \\
\hline 6 & & Literature review, Proof reading & \\
\hline
\end{tabular}

